\title{
Geosmin Sorption on Cyclodextrin Polymers
}

\author{
Redel Gutierrez ${ }^{1,2}$, Niwooti Whangchai ${ }^{1}$, Nakao Nomura ${ }^{3}$ \\ ${ }^{1}$ Faculty of Fisheries Technology and Aquatic Resources, Maejo University, Sansai, Chiang Mai, Thailand \\ ${ }^{2}$ College of Arts and Sciences, Central Luzon State University, Science City of Munoz, Nueva Ecija, Philippines \\ ${ }^{3}$ Graduate School of Life and Environmental Sciences, University of Tsukuba, 1-1-1 Tennodai, Tsukuba, Ibarak, Japan \\ Email: niwooti@hotmail.co.th
}

Received June 2013

\begin{abstract}
Geosmin is one of the major causative compounds of earthy-musty odor and taste (off-flavor) in drinking water (lakes) and in farmed fish. In this study, the sorption of cyclodextrin polymers (CDPs) towards geosmin in aqueous solution was investigated. Sorption kinetics, the effect of solution $\mathrm{pH}$ and contact time on the sorption capability of $\alpha$-, $\beta$ - and $\gamma$-cyclodextrin polymers was discussed. Results disclosed that the sorption of geosmin by the CDPs followed the Ho and McKay kinetic mechanism with the liquid film diffusion as the rate-determining step. Both $\beta$-CDP and $\gamma$-CDP exhibit high removal efficiencies of $93.4 \%$ and $96 \%$, respectively, within 240 minutes at $25^{\circ} \mathrm{C}$ and $\mathrm{pH}$, whilst $\alpha$-CDP was not effective, removing only $40 \%$ geosmin, at an initial concentration of $5 \mu \mathrm{g} \cdot \mathrm{L}^{-1}$ and $5 \mathrm{~g} \cdot \mathrm{L}^{-1}$ of CDP dose. The cyclodextrin polymers can adapt to a wide range of $\mathrm{pH}$ from 3.0 to 11.0 for geosmin adsorption with $\mathrm{pH} 7.0$ as optimum. Results indicate that these sorbents demonstrate significant potential in reducing the concentration of geosmin in water that presents taint problems in both drinking water and fish.
\end{abstract}

Keywords: Geosmin; Cyclodextrin Polymers; Water; Sorption Kinetics

\section{Introduction}

Off-flavor comprises one of the biggest problems in the drinking water industry and aquaculture. Geosmin (trans1, 10-dimethyl-trans-9-decalol) is a naturally occurring germacranoid sesquiterpene, produced by several species of cyanobacteria (i.e. Anabaena, Oscillatoria and Phormodium) and actinobacteria (especially Streptomyces) that impart an earthy-musty odor to water and fish when present at extremely low concentrations [1]. It is one of the most common taste- and odor-causing compounds found in drinking water supplies and in freshwater aquaculture ponds.

The use of conventional treatment techniques such as flocculation, sedimentation and filtration, for the removal of geosmin from water are not effective [2]. Furthermore, electrochemical, biochemical or photochemical degradation are effective processes but expensive. Adsorption is a much better process, in terms of efficiency and economy, than other physical techniques mentioned above. It is one of two treatment methods that have been successfully employed by water treatment plants to remove geosmin, the other being oxidation by ozone.

Suitable adsorbents for water purification are continuously being developed and tested, and cyclodextrin polymers (CDPs) are one of these materials. Several variants of insoluble CDPs were intensively investigated and were found to be very effective in the removal of organic pollutants and heavy metals in water $[3,4]$. It is well known that cyclodextrins polymers $(\alpha-, \beta$ - and $\gamma$-cyclodextrins) form inclusion complexes with molecules having a suitable size and shape. Other than surface adsorption, the removal of organic pollutants from water with CDPs occurs primarily via the formation of these inclusion complexes [3]. In this paper, we report on the application of CDPs ( $\alpha, \beta$ and $\gamma$ forms) in the removal of geosmin from aqueous solutions.

\section{Materials and Methods}

\subsection{Materials}

Synthesized $\alpha$-, $\beta$ - and $\gamma$-CDPs were provided by Kankyo Kougaku Co., Japan and were used without further purification. Geosmin standard solution $\left(2,000 \mathrm{mg} \cdot \mathrm{L}^{-1}\right.$ in methanol) was obtained from Sigma-Aldrich Chemicals Co., USA. Working standard solutions for calibration and spiking were prepared from standard stock solution (100 mg. $\mathrm{L}^{-1}$ ) using Milli-Q water. Solid phase microextraction (SPME) fiber $(50 / 30 \mu \mathrm{m})$ coated with divinylbenzene/carboxen/polymethylsiloxane (DVB/CAR/PDMS) was purchased from Supelco Co. (Bellefonte, PA, USA). All chemical reagents, including methanol and sodium chloride crystals, used in this study were of analytical grade (Labscan Asia Co. Ltd., Thailand). 


\subsection{Extraction and Analytical Methods}

Residual geosmin in the spiked water samples was extracted using headspace SPME. A 50/30 $\mu \mathrm{m}$ DVB/CAR/ PDMS SPME fiber was extended into the headspace of samples (10 mL aqueous solution) placed in a clear 20-mL straight-sided vial. Sodium chloride (1.9 g) and a polytetrafluoroethylene (PTFE)-coated stirring bar were added and the vial was sealed with an aluminum crimp cap fitted with PTFE-faced silicone septum. Extraction time was 15 minutes and extraction temperature was maintained at $65^{\circ} \mathrm{C}$ with vigorous agitation. Geosmin concentration was quantitatively analyzed by gas chromatography-mass spectrometry (GC/MS) using a HP 6890 Network gas chromatograph equipped with a 5973 mass selective detector (Agilent Technologies, USA) by desorbing the fiber in the injection port under a splitless mode at $230^{\circ} \mathrm{C}$ for 5 minutes.

Specific surface area and pore size distributions were determined by $\mathrm{N}_{2}$ gas adsorption using a Brunauer-Emmett-Teller (BET) specific surface analyzer (Autosorb-1-MP Quantachrome, USA). Morphological images of CDPs were acquired by SEM (JSM-5410LV, JEOL, Japan).

\subsection{Sorption Studies and Kinetics}

Spiked standard geosmin solution (initial concentration: $5 \mathrm{ug} / \mathrm{L})$ was prepared and $\mathrm{pH}$-adjusted to 3, 7 and 11 using $1 \mathrm{M} \mathrm{NaOH}$ and $1 \mathrm{M} \mathrm{HCl}$ solutions. One-hundred milliliters of spiked geosmin standard solution was placed in a $250-\mathrm{mL}$ conical flask, $500 \mathrm{mg}$ each of dry cyclodextrin polymer ( $\alpha$-, $\beta$ - and $\gamma$-CDP) was added and the flask securely covered. Three replicates were prepared for each $\mathrm{pH}$ level. A blank (without CDP addition) was included with each isotherm experiment to evaluate sorbate losses by mechanisms other than sorption. Sorption batch experiment was conducted in a thermostat horizontal shaker (WB14/SV1422, Memmert, Germany) set at $25^{\circ} \mathrm{C}$ with an agitation of $100 \mathrm{rpm}$. Samples were collected at various contact times $(0,15,60,120$ and 360 min) and filtered through a $0.45 \mu \mathrm{m}$ membrane filter (Advantech, Japan). Residual geosmin was quantified using HS-SPME and GC-MS. The data obtained were used to calculate the sorption capacity of the CDPs by:

$$
q_{e}=\frac{V\left(C_{0}-C_{e}\right)}{m}
$$

where, $q_{e}$ is the amount of geosmin adsorbed at equilibrium $\left(\mathrm{mol} \cdot \mathrm{L}^{-1}\right) ; C_{0}$ is the initial concentration of geosmin solution $\left(\mathrm{mg} \cdot \mathrm{L}^{-1}\right) ; C_{e}$ is the geosmin aqueous concentration at equilibrium $\left(\mathrm{mg} \cdot \mathrm{L}^{-1}\right) ; V$ is the volume of geosmin solution used (L); and $m$ is the mass of the sorbent used ( $\mathrm{g})$.

\section{Results and Discussion}

\subsection{Effect of Contact Time}

The influence of contact time on the sorption of cyclodextrin polymers toward geosmin is shown in Figure 1. The sorption amount increased evidently with the increase of contact time initially after the first $15 \mathrm{~min}$. Thereafter, the rate of geosmin sorption on the 3 CDPs was found to be slow until the equilibrium was reached and remained constant. Pseudo-equilibrium is achieved after approximately 240 min with maximum geosmin removals of $40 \%, 93.4 \%$ and $96 \%$ by the $\alpha$-CDP, $\beta$-CDP and $\gamma$-CDP, respectively. The results reveal that rapid surface attachment (physical sorption) of geosmin onto the polymers played a major role at the initial stage, which consequently led to a fast initial geosmin removal from the water especially for $\beta$-CDP and $\gamma$-CDP. With time, the active sites on the polymers surfaces gradually decrease and the sorption process becomes slow. Diffusion of geosmin into the polymer network (via mesopores and micropores) possibly took place at this stage causing the particles of CDPs to slowly swell in the solution, until the equilibrium was reached [5].

\subsection{Effect of pH}

The results presented in Figures 2(a) to 2(c) indicate that sorption capacities of the CDPs slightly depend on solution $\mathrm{pH}$. The sorption capacity varies slightly among the $3 \mathrm{pH}$ values, which means that the CDPs can adapt to a wide range of $\mathrm{pH}$ for geosmin sorption from water. The values of the sorption capacity for geosmin on CDPs in pH 7 are slightly higher than the other two pH solutions and therefore, considered the optimal $\mathrm{pH}$. The slight increase at $\mathrm{pH}=7$ could be due to some of CDP may get hydrolyzed, dissociated and reverted back to water-soluble cyclodextrin (CD), which in turn the geosmin molecule formed inclusion complex with $\mathrm{CD}$, increasing the sorption effect. Due to this reason the sorption capacity is higher in $\mathrm{pH}=7$ [6].

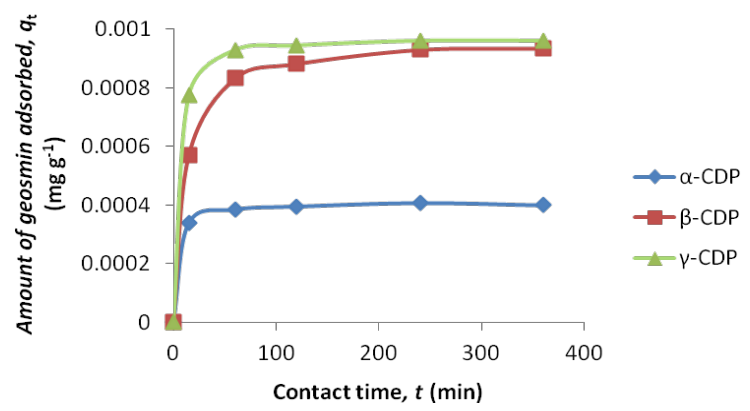

Figure 1. Effect of contact time on the sorption of geosmin (conditions: sorbent: 0.5 g; geosmin initial concentration: 5 $\mu \mathrm{g} \cdot \mathrm{L}^{-1}$; volume: $100 \mathrm{~mL}$; temperature: $25^{\circ} \mathrm{C}$; $\mathrm{pH}=7$ ). 


\subsection{Sorption Kinetics}

The model equation used for fitting geosmin adsorption data was the Ho and McKay Model:

$$
\frac{t}{q_{t}}=\frac{t}{q_{e}}+\frac{1}{k_{2} q_{e}^{2}}
$$

where, $q_{t}$ and $q_{\mathrm{e}}$ are the amount of geosmin adsorbed at time $t$ and at equilibrium $\left(\mathrm{mg} \cdot \mathrm{g}^{-1}\right)$, respectively; $k_{2}$ is the rate constant $\left(\mathrm{g} \cdot \mathrm{mg}^{-1} \cdot \mathrm{min}^{-1}\right)$. The values of $k_{2}$ and experimental $q_{\text {e,expt }}$ were calculated from the intercept and slope of the linear plots of $t / q_{t}$ against $t$ (Figure 1(d)). Table 1 shows the calculated $q_{e \text {,calc }}$ from Equation 1 , the results of kinetic fittings and the parameters associated with Ho and McKay model as well as the regression coefficients. Noteworthy are the high regression coefficients obtained from the plots and the high agreement between the calculated $q_{e, \text { calc }}$ and the experimental $q_{e, \text { expt }}$ values. This suggests the high applicability of the Ho and McKay model in describing the sorption process. Ho and McKay model follows the pseudo-second order mechanism, confirming that sorption of geosmin on CDP was complex, probably initially dominated by surface sorption (physical adsorption, hydrogen bonding) and thereafter, diffusion into the polymer network, chemisorptions via the formation of an inclusion complex due to the presence of the CD sites $[7,8]$.

\subsection{Rate Limiting Step in Sorption Process}

To further interpret the sorption process, the moving boundary model [9-11] was used to discriminate the relative importance of adsorption steps involved to play in the pseudo-second order kinetic model. If the adsorption process was controlled by liquid film diffusion, intra-particle diffusion or chemical interaction, the rate constant can be expressed by Equation (3), (4) and (5), respectively.

$$
\begin{aligned}
& k=-\ln (1-F) \\
& k=1-3(1-F)^{2 / 3}+2(1-F) \\
& k=1-1(1-F)^{1 / 3}
\end{aligned}
$$

where $F$ is the adsorption fraction $\left(q_{t} / q_{e}\right)$, and $k$ is the

Table 1. Ho and McKay sorption kinetic parameters of CDPs for geosmin (conditions: sorbent: $0.5 \mathrm{~g}$; geosmin initial concentration: $5 \mu \mathrm{g} \cdot \mathrm{L}^{-1}$; volume: $100 \mathrm{~mL}$; temperature: $25^{\circ} \mathrm{C} ; \mathbf{p H}=7$ ).

\begin{tabular}{ccccc}
\hline Sorbent & $\begin{array}{c}q_{e, \text { calc }}\left(10^{-4}\right) \\
\left(\mathrm{mg} \cdot \mathrm{g}^{-1}\right)\end{array}$ & $\begin{array}{c}q_{e, \text { expt }}\left(10^{-4}\right) \\
\left(\mathrm{mg} \cdot \mathrm{g}^{-1}\right)\end{array}$ & $\begin{array}{c}k_{2} \\
\left(\mathrm{~g} \cdot \mathrm{mg}^{-1} \cdot \mathrm{min}^{-1}\right)\end{array}$ & $R^{2}$ \\
\hline$\alpha$-CDP & 4.0 & 4.1 & 2997.7 & 0.9869 \\
$\beta$-CDP & 9.3 & 9.5 & 162.3 & 0.9993 \\
$\gamma$-CDP & 9.6 & 9.7 & 492.5 & 0.9999 \\
\hline
\end{tabular}

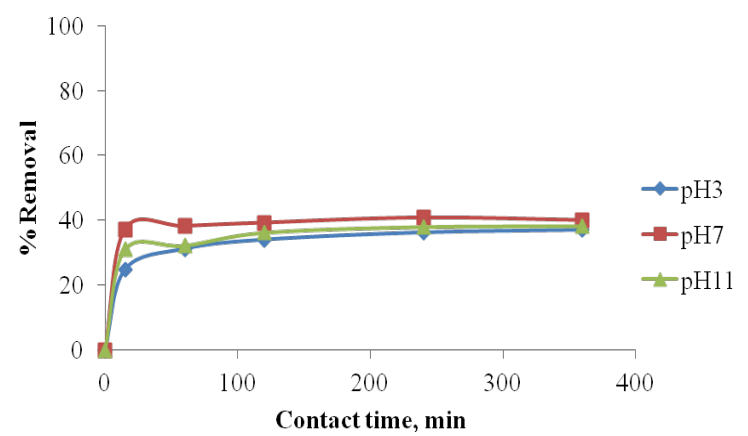

(a)

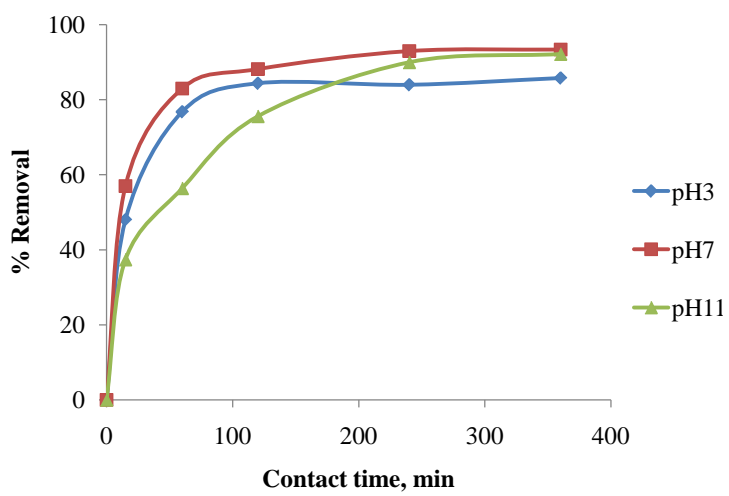

(b)

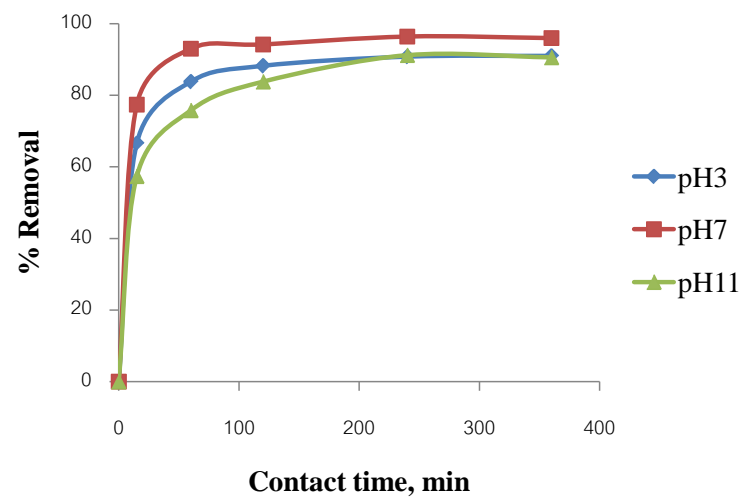

(c)

Figure 2. Effect of pH on sorption of geosmin on $\alpha$-CDP (a), $\beta$-CDP (b) and $\gamma$-CDP (c).

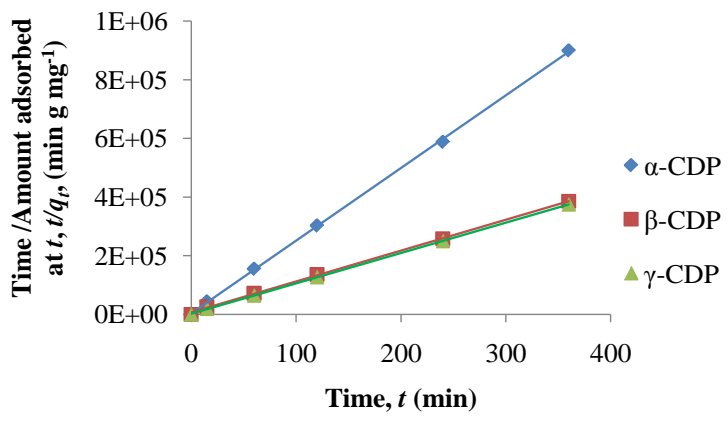

Figure 3. Ho and McKay plots for sorption of geosmin on CDPs (D) (conditions: sorbent: $0.5 \mathrm{~g}$; geosmin initial concentration: $5 \mu \mathrm{g} \cdot \mathrm{L}^{-1}$; volume: $100 \mathrm{~mL}$; temperature: $25^{\circ} \mathrm{C}$; pH = 7). 
sorption rate constant. By plotting a linear relationship of $k$ versus contact time $t$ (min) (Figure 4), the regression coefficients $\left(R^{2}\right)$ for the three sorption steps were obtained, of which the one with the highest $R^{2}$ value was assumed to be the rate controlling step [11]. Result shows that the sorption of geosmin on the CDPs exhibited the highest regression coefficients for Equation (3) (Table 2), indicating that liquid film diffusion was the rate controlling step. Similar findings were reported by Li et al. [5] who found that film diffusion, and neither particle diffusion nor chemical interaction, was the rate limiting step in the sorption process of CDPs for 2,4dichlorophenol. Noteworthy, geosmin has comparable hydrophobicity with 2,4-dichlorophenol, having an octanol-water partition coefficient $\left(\log \mathrm{K}_{\mathrm{ow}}\right.$ ) of 3.57 as compared to the latter's 3.06.

\subsection{Sorption Capacity and Characteristics of CDPs}

The different extents of geosmin sorption among the 3 CDPs may be attributed to BET specific surface area, pore size distribution and the inclusion effect between the sorbent and the sorbate. However, previous studies on CDPs [12,13] showed that BET specific surface area does not play an important role in the sorption process, which is in agreement with the BET result. BET surface area and total pore volume of $\gamma$-CDP are larger than $\alpha$-CDP and $\beta$-CDP, so the sorption capacity of geosmin on $\gamma$-CDP is higher than that of $\alpha$-CDP and $\beta$-CDP. However, $\alpha$-CDP had the lowest sorption capacity among the CDPs despite its higher surface area and total pore volume than $\beta$-CDP (Table 3). Total pore volumes of the CDPs are quite low which ranged from 0.0108 to 0.0139 $\mathrm{cm}^{3} \cdot \mathrm{g}^{-1}$. SEM micrographs of the CDPs (Figure 5) show their spherical morphologies with a rather smooth surface and low porosity. The pore size distributions (Figure 6) show that the observed pore sizes mostly varied between 1.5 and $10 \mathrm{~nm}$. Pore sizes of $2-50 \mathrm{~nm}$ are classified as mesopores, whilst pore sizes of less than $2 \mathrm{~nm}$ are micropores. The results also indicated that a large percentage of the pores in $\gamma$-CDP (60\%) were under $2 \mathrm{~nm}$, which are a favorite adsorption size for geosmin (and 2-methyisoborneol) according to previous reports [14]. The sized-matched structure of geosmin relative to these pores could have contributed to $\gamma$-CDP's high sorption capacity. The sorption mechanisms of CDP are believed

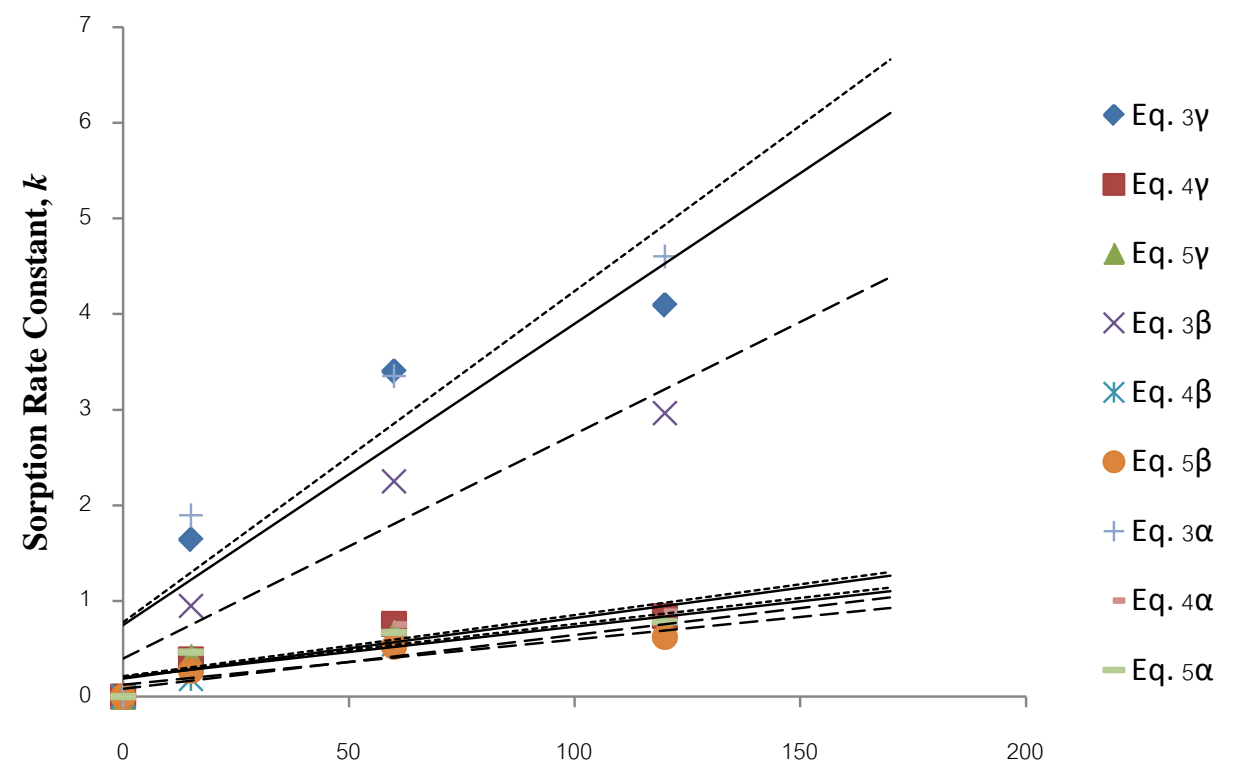

Time, $t$ (min)

Figure 4. Plots of Equations (1), (2) and (3) for geosmin sorption on CDPs.

Table 2. Regression coefficient $\left(R^{2}\right)$ fitted by moving boundary model for geosmin sorption on CDPs.

\begin{tabular}{cccc}
\hline Sorbent & Equation (3) (liquid film diffusion) & Equation (4) (intra-particle diffusion) & Equation (5) (chemical interaction) \\
\hline$\alpha$-CDP & 0.8879 & 0.7793 & 0.7242 \\
$\beta$-CDP & 0.9128 & 0.9096 & 0.8338 \\
$\gamma$-CDP & 0.8516 & 0.7873 & 0.7259 \\
\hline
\end{tabular}


Table 3. BET specific surface area and pore properties of CDPs.

\begin{tabular}{ccccc}
\hline Sorbent & BET Surface Area, $S\left(\mathrm{~m}^{2} \cdot \mathrm{g}^{-1}\right)$ & BET C-constant & Total pore volume, $V_{p}\left(\mathrm{~cm}^{3} \cdot \mathrm{g}^{-1}\right)$ & Average pore radius $(\AA)$ \\
\hline$\alpha$-CDP & 3.07 & 14.09 & 0.0118 & 77.08 \\
$\beta$-CDP & 1.82 & 50.60 & 0.0108 & 121.70 \\
$\gamma$-CDP & 5.37 & 4.36 & 0.0139 & 51.94 \\
\hline
\end{tabular}

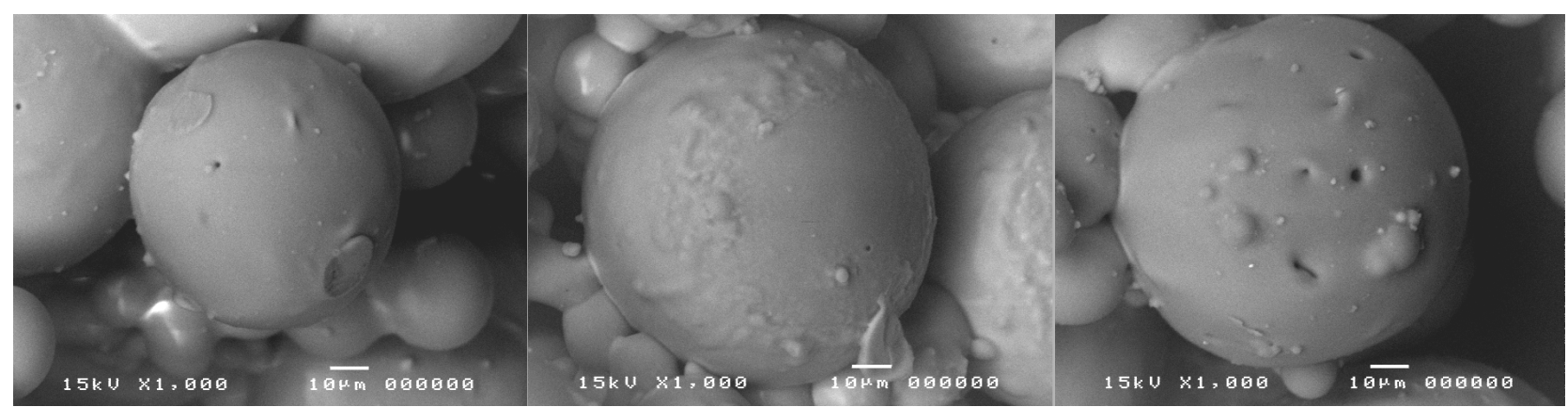

Figure 5. SEM images of $\alpha$-CDP (A) $\beta$-CDP (B) and $\gamma$-CDP (C).

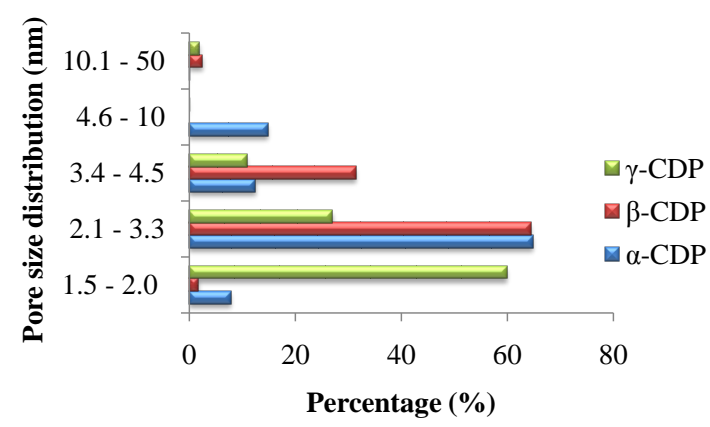

Figure 6. SEM images of $\alpha$-CDP (A) $\beta$-CDP (B) and $\gamma$-CDP (C).

to involve physical sorption on surface and network, hydrogen bonding and inclusion complexation [15]. It is possible that the inclusion effect was strongest in $\gamma$-CDP and weakest in $\alpha$-CD which is dependent on the molar content of CD units in the CDPs.

\section{Conclusion}

The result of this study indicates that $\beta$-CDP and $\gamma$-CDP are effective sorbents for the removal of the taste and odor compound, geosmin, from water. The optimum parameters for equilibrium study at a $0.5 \mathrm{~g}$ sorbent dose are time of contact $240 \mathrm{~min}$ and $\mathrm{pH}$ 7. Sorption kinetics of geosmin by the CDPs followed the Ho and McKay model (pseudo-second order) and the rate limiting step in the process of sorption was film diffusion. The high goodness of fitting for the pseudo-second order model could be ascribed to the nature of cyclodextrin-based polymers with multiple adsorption sites, which are responsible for different adsorption steps. The differences in sorption of geosmin by the CDPs could be attributed to the size- match structure of geosmin relative to the polymers' pores. Future work is required to evaluate the performance of the CDPs' in different types of natural waters to further address the challenges facing the water and aquaculture industries.

\section{Acknowledgements}

The authors thank the Kankyo Kougaku Co., Japan for supplying the polymer materials. Support from the Faculty of Fisheries Technology and Aquatic Resources, and Institute of Product and Quality Standards in Maejo University, Thailand and the Graduate School of Life and Environmental Science, University of Tsukuba, Japan for the laboratory instruments and research facilities are greatfully appreciated.

\section{REFERENCES}

[1] J. A. Billica, J. Oropeza and G. K. Elmund, "Monitoring to Determine Geosmin Sources and Concentrations in a Northern Colorado Reservoir," Proceedings of the National Water Quality Monitoring Council 7th National Monitoring Conference, City of Fort Collins Utilities, Fort Collins, Colorado, 2010, pp. 1-14.

[2] D. Bruce, P. Westerhoff and A. Brawley-Chesworth, "Removal of 2-Methylisoborneol and Geosmin in Surface Water Treatment Plants in Arizona," Journal of Water Supply: Research and Technology, AQUA, Vol. 4, No. 51, 2002, pp. 183-197.

[3] B. Mamba, R. Krause, T. Malefetse, S. Mhlanga, S. Sithole, K. Salipira and E. N. Nxumalo, "Removal of geosmin and 2-Methylisorboneol (2-MIB) in Water from Zuikerbosch Treatment Plant (Rand Water) Using â-cyclodextrin Polyurethanes," Water SA, Vol. 2, No. 33, 2007.

[4] L. Ducoroy, M. Bacquet, B. Martel and M. Morcellet, 
"Removal of Heavy Metals from Aqueous Media by Cation Exchange Nonwoven PET Coated with b-CycloDextrin-polycarboxylic moieties," Reactive and Funtional Polymers, Vol. 68, No. 2, 2008, pp. 594-600. http://dx.doi.org/10.1016/j.reactfunctpolym.2007.10.033

[5] N. Li, Z. Mei and S. Ding, "2,4-Dichlorophenol Sorption on Cyclodextrin Polymers," Journal of Inclusion Phenomena and Macrocyclic Chemistry, Vol. 68, No. 1-2, 2010, pp. 123-129.

http://dx.doi.org/10.1007/s10847-010-9751-2

[6] K. Srinivasan and T. Stalin, "Sorption onto Insoluble $\beta$ cyclodextrin Polymer for 2,4-Dinitrophenol," Journal of Inclusion Phenomena and Macrocyclic Chemistry, Vol. 73, No. 1-4, 2012, pp. 321-328. http://dx.doi.org/10.1007/s10847-011-0059-7

[7] Y. S. Ho and G. McKay, "Pseudo-Second Order Model for Sorption Processes,” Process Biochemistry, Vol. 34, No. 5, 1999, pp. 451-465. http://dx.doi.org/10.1016/S0032-9592(98)00112-5

[8] Y. S. Ho and G. McKay, "Kinetic of Sorption of Basic Dyes from Aqueous Solution by Sphagnum Moss Peat," The Canadian Journal of Chemical Engineering, Vol. 76, No. 4, 1998, pp. 822-827. http://dx.doi.org/10.1002/cjce.5450760419

[9] G. E. Boyd, A. W. Adamson and L. S. Meyers, "The Exchange Adsorption of Ions from Aqueous Solutions by Organic Zeolites. II. Kinetics,” Journal of the American Chemical Society, Vol. 69, No. 11, 1947, pp. 2836-2848. http://dx.doi.org/10.1021/ja01203a066

[10] A. Kadous, M. A. Didi and D. Villemin, “A New Sorbent for Uranium Extraction: Ethylenediamino Tris(methylenephosphoric) Acid Grafted on Polystyrene Resin," Journal of Radioanalytical and Nuclear Chemistry, Vol.
284, No. 2, 2010, pp. 431-438. http://dx.doi.org/10.1007/s10967-010-0495-7

[11] H. Liu, X. Cai, Y. Wang and J. Chen, "Adsorption Mechanism-based Screening of Cyclodextrin Polymers for Adsorption and Separation of Pesticides from Water," Water Research, Vol. 45, No. 11, 2011, pp. 3499-3511. http://dx.doi.org/10.1016/j.watres.2011.04.004

[12] C. Gazpio, M. Sanchez, J. R. Isasi, I. Velaz, C. Martın and A. Zornoza, "Sorption of Pindolol and Related Compounds by a $\beta$-Cyclodextrin Polymer: Isosteric Heat of Sorption,” Carbohydrate Research, Vol. 71, 2008, pp. 140-146.

[13] G. Crini, H. N. Peindy, F. Gimbert and C. Robert, "Removal of C. I. Basic Green 4 (Malachite Green) from Aqueous Solutions by Adsorption Using Cyclodextrinbased Adsorbent: Kinetic and Equilibrium Studies," Separation and Purification Technology, Vol. 53, No. 1, 2007, pp. 97-110. http://dx.doi.org/10.1016/j.seppur.2006.06.018

[14] R. Chen, Q. Xue, Z. Zhang N. Suguira, Y. Yang, M. Li, N. Chen, Z. Ying and Z. Lei, "Development of Long-LifeCycle Tablet Ceramic Adsorbent for Geosmin Removal from Water Solution,” Applied Surface Science, Vol. 257, No. 6, 2011, pp. 2091-2096. http://dx.doi.org/10.1016/j.apsusc.2010.09.055

[15] G. Crini, S. Bertini, G. Torri, A. Naggi, D. Sforzini, C. Vecchi, L. Janus, Y. Lekchiri and M. Morcellet, "Sorption of Aromatic Compounds in Water Using Insoluble Cyclodextrin Polymers,” Journal of Applied Polymer Science, Vol. 68, No. 12, 1998, pp. 1973-1978. http://dx.doi.org/10.1002/(SICI)1097-4628(19980620)68: 12<1973::AID-APP11>3.0.CO;2-T 